\title{
Isolation and Identification of Pathogenic Bacterial Contaminants associated with Poultry
}

\author{
Rujuta Kedar Karkhanis*, Yashsvi Udaybhai Raval, \\ Devikaben Bharatbhai Vishani and Dhruv Girishbhai Patel
}

Department of Microbiology, Parul Institute of Applied Science, Waghodia, India

*Corresponding author

\section{Keywords}

Salmonella spp., Escherichia coli, poultry farm, feeding operation, microbiological analysis

\section{Article Info}

Accepted:

12 April 2021

Available Online:

10 May 2021
The study was conducted aiming at the isolation and identification of Salmonella and Escherichia coli (E. coli) from different poultry farm in Padra Village, Gujarat, India. Drinking water samples were collected from feeding operation of two different poultry farms and were analysed for the presence of Salmonella spp. and Escherichia coli using microbiological analysis. The samples were analysed by culturing in different media such as nutrient broth (NB), nutrient Agar (NA), BGA (brilliant-green Agar), MCA (MacConkey), EMB (eosin methylene blue), and LuriaBertani media. Salmonella spp. and Escherichia coli were tested against 5 anti- microbial agents: Gentamicin, Streptomycin, Ampicillin, Penicillin, Chloramphenicol using the Kirby-Bauer disc diffusion method. The result of this research showed the presence of aerobic bacteria and also the resistant of bacteria to certain antibiotics in water samples. Strict hygienic practices and biosecurity measures should be instituted and maintained both at feed mills and poultry farms so as to eliminate contamination associated with poultry. The widespread occurrence of Salmonella spp. and E. coli in poultry feeds reinforces the need for effective control measures, hygiene in processing and handling of feeds.

\section{Introduction}

The intense international trade of animals and animal product facilitates the spread of Salmonella spp. making gastrointestinal disorder a worldwide public-health subject, accountable for serious economic losses to the poultry trade and governments (10). Contaminated poultry products are identified as the principal sources of Salmonella resulting in food borne illness in humans. Handling of raw poultry carcasses and products and consumption of undercooked poultry meat are the most causes of infection (20). Salmonella spp. and E. coli cause food borne sickness that transmitted through poultry meat (6). The genus Salmonella consists of quite 2300 serologically 
distinguishable variants (20). Though humans will become infected by Salmonella spp. through an outsized range of foodstuff, poultry meat and eggs are among the foremost often involved sources of human Salmonella outbreaks (10). Salmonellosis are major bacterial diseases in poultry trade worldwide (9).

The US annual salmonellosis burden was recently estimated to be in the order of 1.5 million cases (including over 580 deaths), $95 \%$ of those cases were attributed to food borne infection (20).

Divided into two distinct serovar groups, Typhoidal and non-Typhoidal, based on the form of infection, non-Typhoidal Salmonella is one among the leading causes of food borne illnesses worldwide with an estimated 93.8 million cases and 155,000 deaths annually thanks to complications from gastrointestinal infections (21). Most of these cases occur as a results of consuming contaminated foods, significantly foods of animal origin (3).

Throughout the past twenty years, severe outbreaks of gastrointestinal sickness have occurred by food borne infective E. coli, particularly 0157:H7. It had been reported that in India around 1.8 million people died from diarrheal diseases mostly due to contaminated food and water within the year 2005 .

Among the diseases some are typically severe and generally fatal infections like communicable disease, endocarditis, tract infection, septicemia, epidemic diarrhea of adults and youngsters and yolk sac infection, omphalitis, cellulitis, swollen head syndrome, coligranuloma and colibacillosisn (18).

Enteritis caused by E. coli (colibacilliosis) could even be a vital sickness inside the poultry trade as a results of increased mortality and diminished performance. E. coli might even be variety one reason behind acute kidney disease in children (12). The ultimate goal of controlling food borne hazards is to cut back the danger of disease to consumers, and reduce the economic burden associated with food borne illness (20). This study was therefore designed to attain isolation, identification and antimicrobial susceptibility of E. coli and Salmonella spp. related to poultry in Vadodara, Gujarat (7).

\section{Materials and Methods}

\section{Study area}

The study was conducted in two different commercial poultry farm close to Padra village in Vadodara, Gujarat, India.

\section{Sample collection}

Sample of unpurified water from feeding operation was collected from two commercial poultry farm. Samples were obtained in sterilized baggage, glass bottles and properly labeled.

\section{Chemicals used}

Peptone, Luria Bertani broth, Brilliant green agar, Eosin methylene blue agar, nutrient agar, Nutrient broth, Nutrient agar, Crystal violet, Iodine, Alcohol, Safranin, Antibiotics (Gentamicin, Streptomycin, Chloramphenicol, Ampicillin and Penicillin), Tryptophan broth, Urease broth, Triple sugar iron agar, Simmon citrate agar, Kovac's reagent, Methyl Red Voges Proskauer broth, Methyl red reagent, Hydrogen peroxide, Distilled water.

\section{Apparatus used}

Autoclave, Laminar airflow, Incubator, Petri dishes, Conical flasks, Test tubes, glass slides, pipettes, Microscope, weigh machine 


\section{Isolation method}

Non-selective pre-selective enrichment: The water sample obtained from feeding operation were pre-enriched in $225 \mathrm{ml}$ buffered peptone water (BPW, Oxoid) and incubated at $37^{\circ} \mathrm{C}$ for $24 \mathrm{~h}$.

Selective- enrichment: $10 \mathrm{ml}$ BPW preenrichment step transferred to $100 \mathrm{ml}$ Luria Bertani broth (LB broth) for selective enrichment, and incubated at $37^{\circ} \mathrm{C}$ for $24 \mathrm{~h}$

Serial six-fold dilution in peptone water was prepared $\left(10^{-1}\right.$ to $\left.10^{-6}\right)$ for test samples. All test tubes and pipette were autoclaved before their utilization and were corked properly, labeled.

Selective agar plating: $0.5 \mathrm{ml}$ solution of $10^{-6}$ tube was taken on brilliant green Agar plate (BGA) and MacConkey agar plate. Spread out using glass spreader and Plates were labelled, inverted and incubated overnight (18-24 hours) at $37^{\circ} \mathrm{C}$.

Sub-cultivation: a $10 \mu \mathrm{l}$ wire loop was used to pick a suspect colony that caused the colour of the medium to vary from yellow to red/ pink were sub-cultivated unto nutrient agar and incubated overnight (18-24 hours) at $37^{\circ} \mathrm{C}$.

On removal from the incubator, plates were stored in a refrigerator at $4^{\circ} \mathrm{C}$, ready for biochemical analysis and gram staining (1).

\section{Microbiological and biochemical characteristic of isolated bacteria}

The Gram staining was performed to observe its cellular morphology and gram nature of the bacteria. The biochemical characterization of the strains were also performed. Test like Catalase test, sugar fermentation using Triple sugar iron test, Indole test, Citrate test, Urease test and Methyl red test were performed (1).

\section{Antibiotic sensitivity test for isolates}

Antibiotic sensitivity tests were applied on the various bacteria isolated. This was done using the disc diffusion technique as explained by Kirby-Bauer, the in-vitro antibiotic testing of bacterium was done on Nutrient agar, $0.1 \mathrm{ml}$ smeared on the surface of the medium before putting the antibiotic discs and incubating for 24 hours before taking the readings of the diameter zones of inhibition using a millimetre rule (7).

\section{Results and Discussion}

The water from the feeding operations for poultry is an excellent source of harmful bacteria. In this study we have studied bacterial population in water from feeding operations.

For characterized bacterial isolation gram staining and biochemical test were performed. Biochemical test were performed such as urease test, methyl red test, catalase test, Indole test, Citrate test, triple sugar iron (Table 1).

\section{Antibiotic susceptibility test}

\section{Antibiotic susceptibility test (Sample 1)}

The antibiotic sensitivity test for Salmonella in Sample 1, resulted that the bacteria is sensitive to Gentamicin, Streptomycin, Chloramphenicol with a sensitivity zone of $7 \mathrm{~mm}, 6 \mathrm{~mm}, 7 \mathrm{~mm}$ respectively and resistance to Ampicillin and Kanamycin (no zone)

For E. coli in Sample 1, test resulted that the bacteria is sensitive to Gentamicin, Streptomycin, Chloramphenicol with a sensitivity zone of $7 \mathrm{~mm}, 5 \mathrm{~mm}, 2 \mathrm{~mm}$ respectively and resistance to Ampicillin (no zone) 


\section{Antibiotic susceptibility test (Sample 2)}

The antibiotic sensitivity test for Salmonella in Sample 2, resulted that the bacteria is sensitive to Gentamicin, Streptomycin, Chloramphenicol with a sensitivity zone of $8 \mathrm{~mm}, 7 \mathrm{~mm}, 5 \mathrm{~mm}$ respectively and resistance to Ampicillin and Penicillin (no zone)

For E. coli in Sample 2, test resulted that the bacteria is sensitive to Gentamicin, Streptomycin, Chloramphenicol with a sensitivity zone of $7 \mathrm{~mm}, 8 \mathrm{~mm}, 3 \mathrm{~mm}$, respectively and resistance to Ampicillin and Penicillin (no zone)

The present study indicates that Salmonella and E. coli bacteria are present within the water samples collected from poultry farms almost Padra village, Vadodara, Gujarat, India. This could be due to the activities of humans, soiled contamination, and conjointly the ability of the organism to survive throughout a large selection of habitats. The water provided to chickens are involved in the spread of Salmonella sp. among poultry and potential transmission to humans. The presence of these microorganisms within the poultry feeds suggested poor sanitary.

The presence of these two organisms (E. coli and Salmonella typhi) demonstrated a possible health risk as a results of the organisms are infective and can cause ill health in humans and animals; though $S$. Typhi might be a strict human organism and has not been according to cause ill health in animals. The water samples for Salmonella and E. coli revealed that, the sensitivity zone was shaped for Gentamycin, streptomycin and chloramphenicol with resistance to ampicillin and penicillin. The organisms isolated throughout this study were most in danger of gentamicin, streptomycin and chloramphenicol. This will be often altogether chance because of less usage of these antibiotics in feeds leading to less exposure of the organism to the antibiotics. Additionally, the drugs are disinfectant in their modes of action. Variety of those bacterial contaminants will grow or survive throughout food process and storage. Food contamination with these pathogens will occur at multiple steps on the food chain, alongside production, processing, distribution, retail marketing, and handling or preparation. This study shows the importance of maintaining hygiene and sanitation to regulate the expansion of Salmonella and E. coli for public safety.

From the study we found bacteria which is harmful to the human. Results shows that there is lack of sanitization and proper hygiene management. The Salmonella and E. coli bacteria found in the water fed to the chickens makes them a carrier and then the bacteria are transferred to humans through the consumption of poultry meat. Various gastrointestinal diseases are caused in humans by the consumption of contaminated poultry meat. Poor management of farming, overcrowding, dirty sanitation environment, bad ventilation, poor feed quality and stress will cause chicken to infect with diseases. Antibiotics should be used carefully so that a bacterium doesn't become resistant to antibiotics. Therefore, the way to take effective measures to stop and control infectious diseases from chicken is the task. Hence, it is required to implement a stricter hygiene and sanitation standard in poultry farms. For further studies bacteriophage may be thought of for the reduction of contamination in poultry feeds. Bacteriophages are viruses that are specific obligate bacterial parasites and typically possess high specificity for one bacterial species. Generally, once the bacteriophage inserts its genome into the bacteria, it'll use the bacteria's replicating machinery to produce more phages that are released upon bacterial cell lysis. 
Table.1 Biochemical characterization of Salmonella and E.coli from Water sample

\begin{tabular}{|c|c|c|c|c|}
\hline \multirow[t]{3}{*}{ Biochemical tests } & \multicolumn{4}{|c|}{ Bacteria } \\
\hline & \multicolumn{2}{|c|}{ Sample 1} & \multicolumn{2}{|c|}{ Sample 2} \\
\hline & Salmonella & E. coli & Salmonella & E. coli \\
\hline $\begin{array}{c}\text { Triple sugar agar } \\
\text { test }\end{array}$ & $\mathrm{K} / \mathrm{A}+, \mathrm{H}_{2} \mathrm{~S}+$ & $\mathrm{K} / \mathrm{A}+, \mathrm{H}_{2} \mathrm{~S}+$ & $\mathrm{K} / \mathrm{A}+, \mathrm{H}_{2} \mathrm{~S}+$ & $\mathrm{K} / \mathrm{A}+, \mathrm{H}_{2} \mathrm{~S}+$ \\
\hline Indole test & + & + & + & + \\
\hline Citrate test & + & - & + & - \\
\hline Urease test & - & - & - & - \\
\hline Catalase test & + & + & + & + \\
\hline Methyl red test & + & + & + & + \\
\hline
\end{tabular}

Notes: K, Alkali (red); A, Acid (yellow);

+ , positive; - , negative; \pm , positive/negative

Antibiotic susceptibility test (Sample.1)

Table.1.1 Salmonella

\begin{tabular}{|c|c|}
\hline Antibiotics $(\boldsymbol{\mu g})$ & $\begin{array}{c}\text { Zone } \\
\text { measurement } \\
(\mathbf{m m})\end{array}$ \\
\hline Gentamicin (50) & 7 \\
\hline Streptomycin (10) & 6 \\
\hline Ampicillin (10) & 0 \\
\hline Penicillin (2) & 0 \\
\hline $\begin{array}{c}\text { Chloramphenicol } \\
\text { (50) }\end{array}$ & 7 \\
\hline
\end{tabular}

Table.1.2 E. coli

\begin{tabular}{|c|c|}
\hline Antibiotics $(\boldsymbol{\mu g})$ & $\begin{array}{c}\text { Zone } \\
\text { measurement } \\
(\mathbf{m m})\end{array}$ \\
\hline Gentamicin (50) & 7 \\
\hline Streptomycin (10) & 5 \\
\hline Ampicillin (10) & 0 \\
\hline Penicillin (2) & 0 \\
\hline $\begin{array}{c}\text { Chloramphenicol } \\
(\mathbf{5 0})\end{array}$ & 2 \\
\hline
\end{tabular}


Antibiotic susceptibility test (Sample.2)

Table.2.1 Salmonella

\begin{tabular}{|c|c|}
\hline Antibiotics $(\boldsymbol{\mu g})$ & $\begin{array}{c}\text { Zone } \\
\text { measurement } \\
(\mathbf{m m})\end{array}$ \\
\hline Gentamicin (50) & 8 \\
\hline Streptomycin (10) & 7 \\
\hline Ampicillin (10) & 0 \\
\hline Penicillin (2) & 0 \\
\hline $\begin{array}{c}\text { Chloramphenicol } \\
\text { (50) }\end{array}$ & 5 \\
\hline
\end{tabular}

Table.2.2 E. coli

\begin{tabular}{|c|c|}
\hline Antibiotics $(\boldsymbol{\mu g})$ & $\begin{array}{c}\text { Zone } \\
\text { measurement } \\
(\mathbf{m m})\end{array}$ \\
\hline Gentamicin (50) & 7 \\
\hline Streptomycin (10) & 8 \\
\hline Ampicillin (10) & 0 \\
\hline Penicillin (2) & 0 \\
\hline $\begin{array}{c}\text { Chloramphenicol } \\
(\mathbf{5 0})\end{array}$ & 3 \\
\hline
\end{tabular}

Fig.1 TSI test result

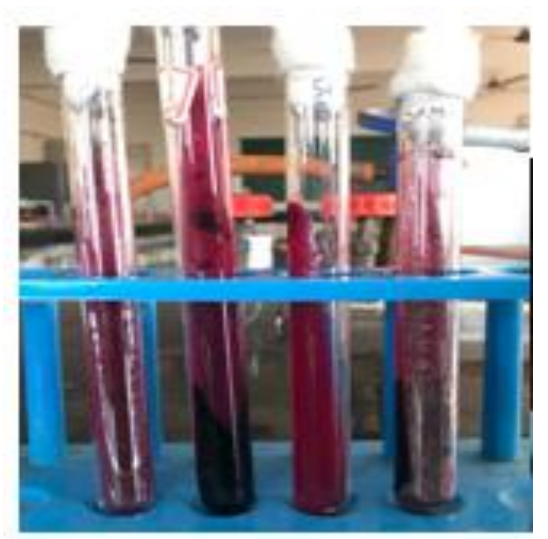

Fig.2 Indole test result

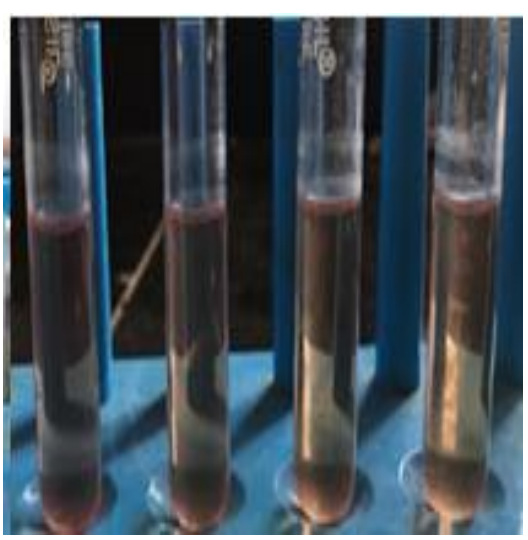

Fig.3 Citrate test result

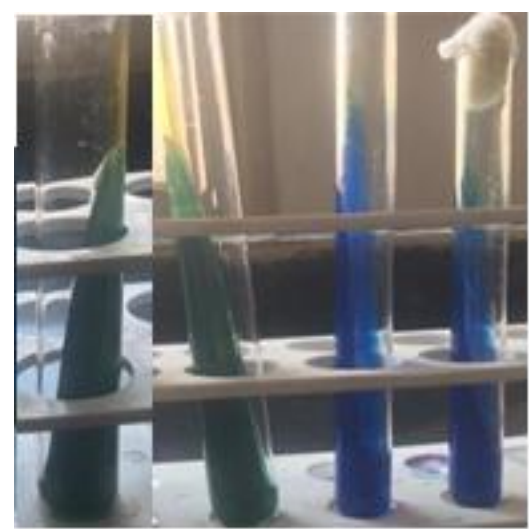


Fig.4 Urease test result
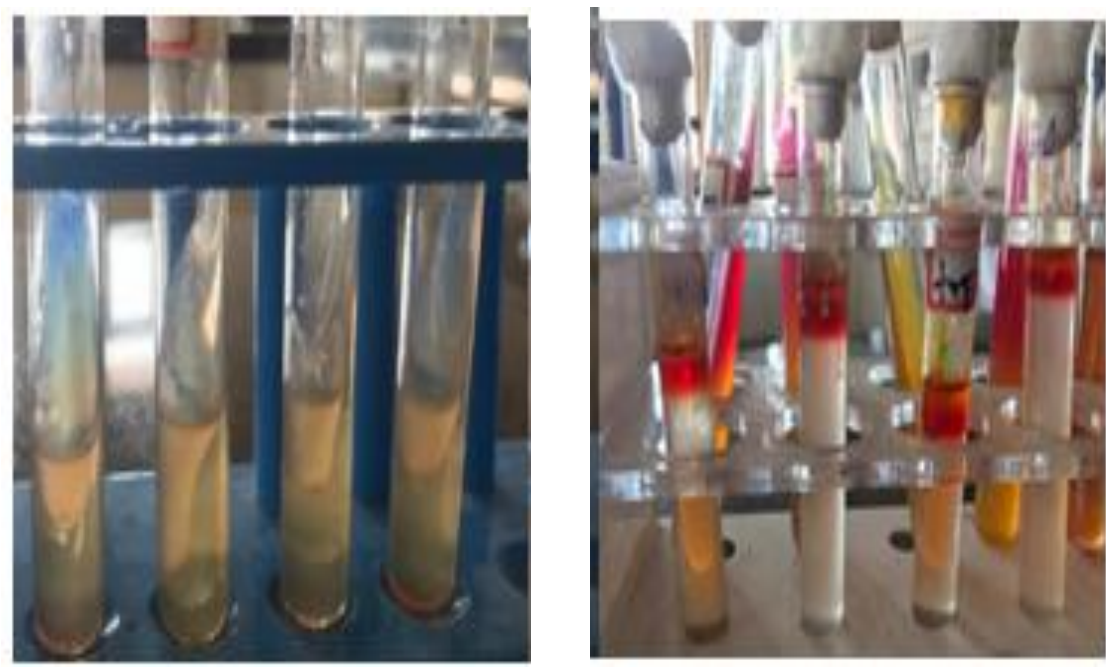

Gram staining
Fig.6 MR test result

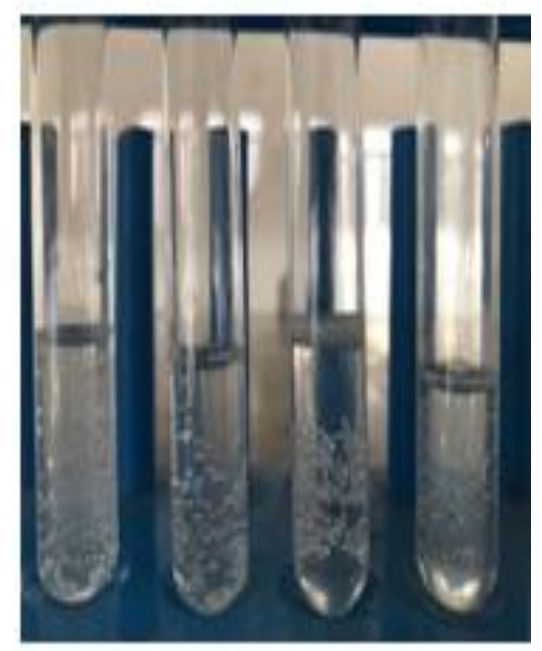

Sample.1
Salmonella

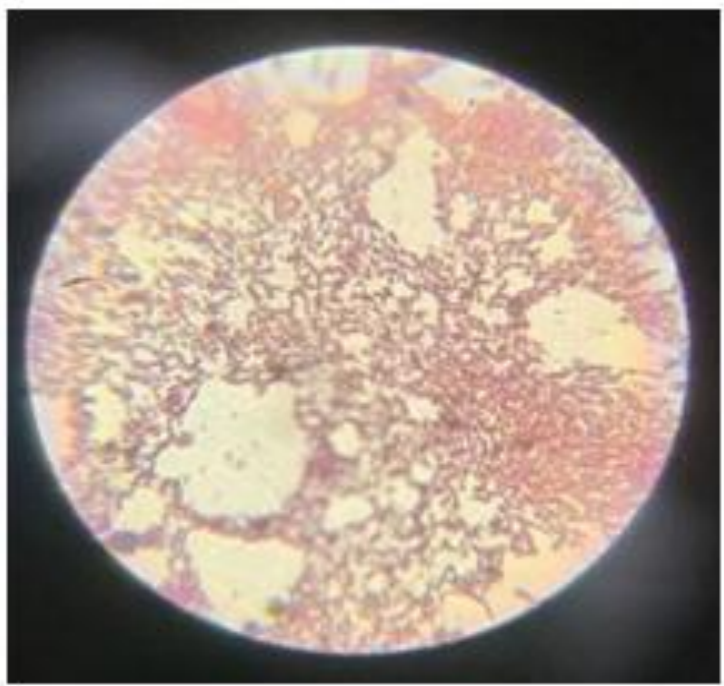

E. coli

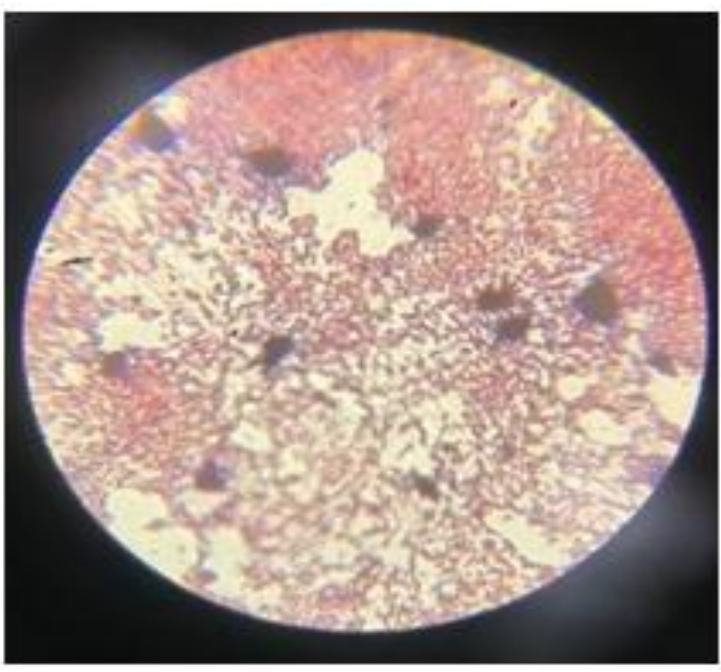




\section{Sample.2}

Salmonella

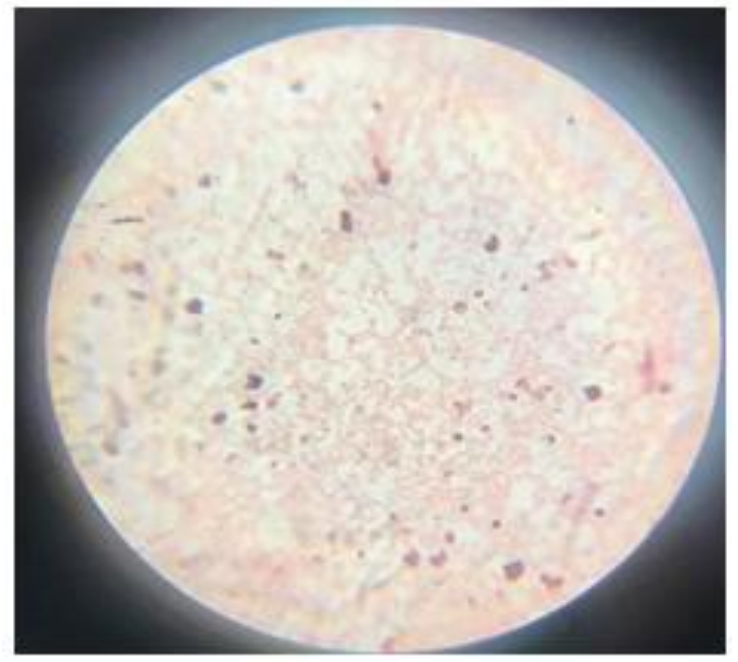

Antibiotic susceptibility test (Sample.1)

Salmonella

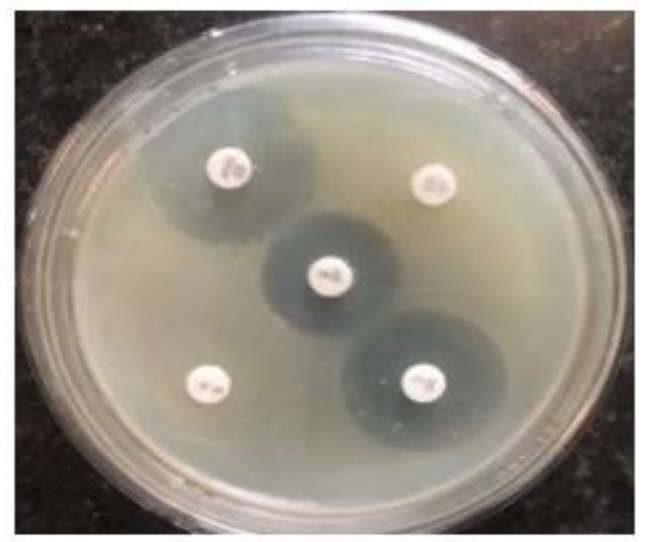

E. coli

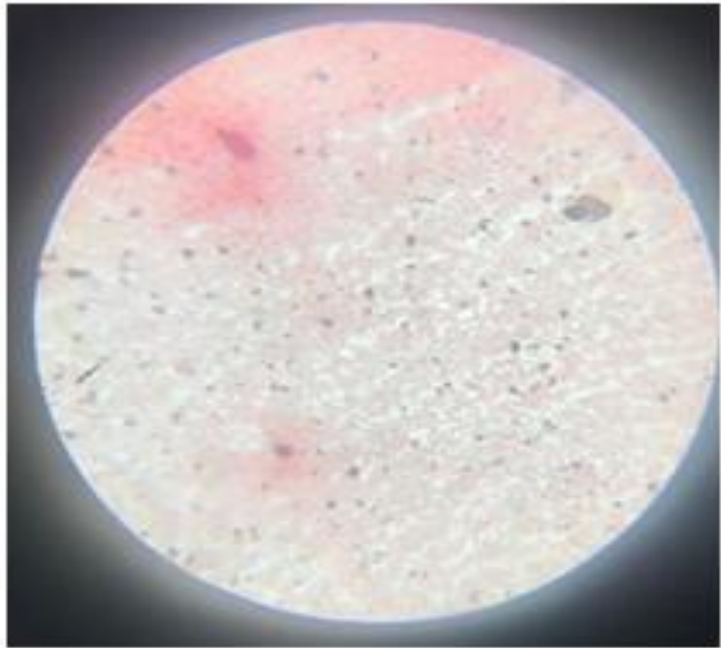

E. coli

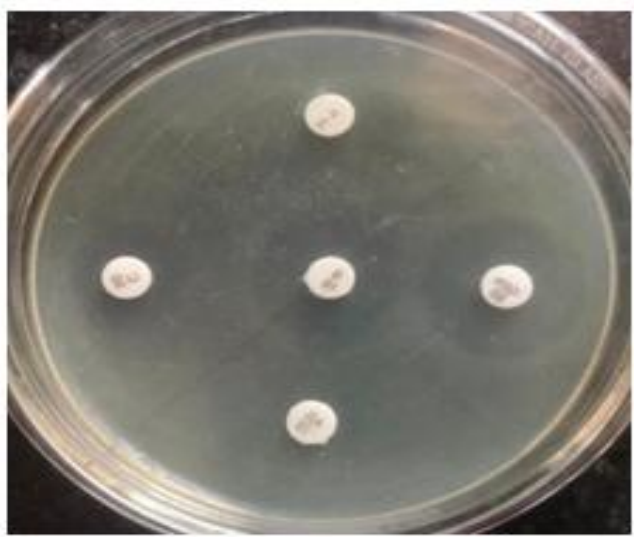




\section{Antibiotic susceptibility test (Sample.2)}

Salmonella

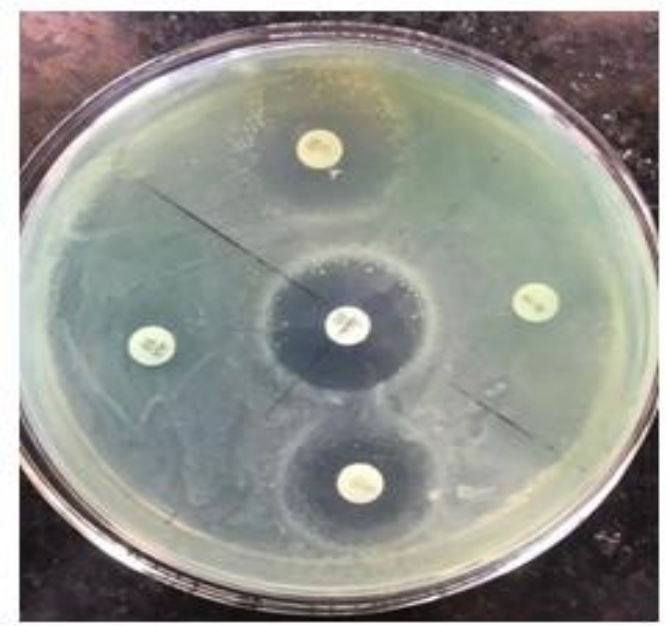

Lytic bacteriophages infect bacteria leading to rapid host death with minimal probability of phage transduction (Monk et al., 2010). The virucidal impact of phage and also the $\mathrm{pH}$ of water needed for bacteriophage to survive may be further study area.

\section{Acknowledgment}

I would to like to thank to the Department of Microbiology of Parul Institute of Applied Science, Parul University for providing the necessary facilities to carry out the my thesis work. Also I want to thank my guide for her consistent guidance and encouragement during my thesis work.

\section{References}

1. Adeyanju. G. T., Ishola. O., (2014), Salmonella and Escherichia coli contamination of poultry meat from a processing plant and retail markets in Ibadan, Oyo State, Nigeria. Springer Plus. 3:139, pp. 1-9

2. Chao M. R., Hsien. C. H, Yeh. C. M., Chou S. J., Chu. C. Su. Y. C, and Yu. C. Y, (2007), Assessing the Prevalence of
E. coli

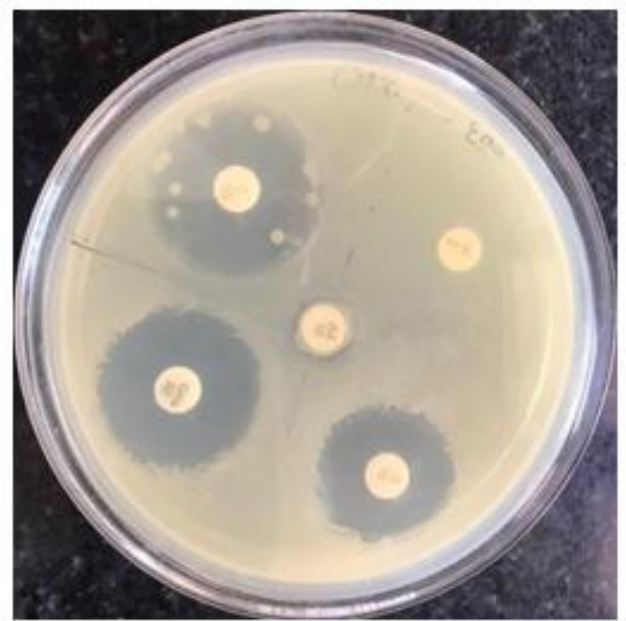

Salmonella enterica in Poultry Hatcheries by Using Hatched Eggshell Membranes, Poultry Science, 86, pp-1651-1655.

3. Chen. M. H., Wang. S. W, Hwang W. Z, Tsai S. J., Hsih. Y. C, Chiou C. S, and Tsen H.Y, (2010), Contamination of Salmonella Schwarzengrund cells in chicken meat from traditional marketplaces in Taiwan and comparison of their antibiograms with those of the human isolates, Poultry Science (89), pp: 359-365

4. Cox. N. A, Cason. J. A, Buhr. R. J, Richardson. K. E, Richardson. L. J, Rigsby. L. L, and Fedorka-Cray P. J, (2013), Variations in preenrichment $\mathrm{pH}$ of poultry feed and feed ingredients after incubation periods up to 48 hours, J. Appl. Poult. Res. (22), pp: 190-195

5. Bushra. M. K., Haifa. N. M., (2019), Bacterial Contaminants Associated with Poultry Feeds, Indian Journal of Public Health Research \& Development, 10(9), pp. 964-969

6. Yulistiani. R., Praseptiangga. D., Supyani, Sudibya, (2019), Occurrences of Salmonella spp. and Escherichia coli in chicken meat, intestinal contents and rinse water at slaughtering place from traditional 
market in Surabaya, Indonesia, Materials Science and Engineering, 633(012007), pp:1-6

7. Mamman, P. H. and Ndakotsu, J. P., Antibiogram of Aerobic Bacteria Isolated from Poultry Feeds in Zaria, Nigeria, Nigerian Veterinary Journal 36 (2), pp: 1184-1191

8. Chowdhuri. A., Iqbal. A., Giasuddin. M., and Bhuiyan. A. A., (2011), Study on Isolation and Identification of Salmonella and Escherichia coli from Different Poultry Feeds of Savar Region of Dhaka, Bangladesh, J. Sci. Res. 3 (2), pp: 403-411

9. Md. Manirul Islam and Chul-Ju Yang, (2017), Efficacy of mealworm and super mealworm larvae probiotics as an alternative to antibiotics challenged orally with Salmonella and E. coli infection in broiler chicks, Poultry Science (96), pp:2734

10. Soria. M. C, Soria. M. A, Bueno. D. J., Godano. E. I., G'omez. S. C, ViaButron. I. A., Padin. V. M., and Rog'e. A. D., (2017), Salmonella spp. contamination in commercial layer hen farms using different types of samples and detection methods, Poultry Science, (96), pp:2820-2830

11. Ar'Quette. G., Salina. P., Schwarz. J., Hashem. F., and Vimini. B., (2017), Reduction of Salmonella in ground chicken using a bacteriophage, Poultry Science (96), pp:2845-2852

12. Kassaify. Z. G., Mine. Y., (2004), Nonimmunized Egg Yolk Powder Can Suppress the Colonization of Salmonella typhimurium, Escherichia coli O157:H7, and Campylobacter jejuni in Laying Hens, Poultry Science (83), pp:1497-1506

13. Bartkiene. E., Ruzauskas. M., Bartkevics. V., Pugajeva. I., Zavistanaviciute. P., Starkute. V., Zokaityte. E., Lele. V., Dauksiene. A., Grashorn.M., Hoelzle. L. E., Mendybayeva. A., Ryshyanova. R., and Gruzauskas, R., (2020), Study of the antibiotic residues in poultry meat in some of the EU countries and selection of the best compositions of lactic acid bacteria and essential oils against Salmonella enterica, Poultry Science, 99(8), pp:40654076

14. Sudershan. R. V., Kumar. R. N., Kashinath. L., Bhaskar.V., Polasa. K., (2014), Food borne Infections and Intoxications in Hyderabad India, Epidemiology Research International, vol. 2014, pp: 1-5

15. Crump. J. A., Griffin. P. M., Angulo. F. J.,(2002), Bacterial Contamination of Animal Feed and Its Relationship to Human Food borne Illness, Clinical Infectious Diseases, 35(7), pp:859-865

16. Chowdhuri1.A., Iqbal1.A., Giasuddin. M., and Bhuiyan. A. A., (2011), Study on Isolation and Identification of Salmonella and Escherichia coli from Different Poultry Feeds of Savar Region of Dhaka, Bangladesh, Journal of scientific research, 3 (2), pp:403-411

17. Akond. M. A., Alam. S., Hassan. S. M. R., Shirin. M., (2009), Antibiotic Resistance of Escherichia coli Isolated From Poultry and Poultry Environment of Bangladesh, Internet Journal of Food Safety, 11, pp: 1923

18. Gomes T A, Elias W P, Scaletsky I C, Guth BE, Rodrigues J F, Piazza R M, Ferreira L C, Martinez MB, (2016), Diarrheagenic Escherichia coli, Braz J Microbiol,47(1), pp:3-30.

19. Pai M, Kang G, Ramakrishna B S, Venkataraman A, Muliyil J, (1997), An epidemic of diarrhoea in south India caused by enteroaggregative Escherichia coli. Indian J Med Res, 106, pp:7-12.

20. Maung. S. M.,(2004), Thesis Epidemiology Of Salmonella Contamination Of Poultry Meat Products: Knowledge Gaps In The Farm To Store Products, pp:1-101

21. Sexton. T. L., (2017), Thesis Salmonella Contamination In Poultry-Are We Missing A Potential Reservoir?, pp:1-66 
22. Nayak. R. R., (2000), Thesis Food borne Pathogens in Poultry Production and Postharvest Control, pp:1-180

23. Saeed. H. I. M., (2010), Isolation and identification of Salmonella from the environment of traditional poultry farms in Khartoum North, pp:1-64

24. Nahid. T. H. A., (2010), Bacterial Contamination in Poultry Feed in Khartoum State, pp:1-50

25. Onyeze. R. C, Onah. G. T and Eluke. O. C., (2013), Bacterial Contaminants Associated With Commercial Poultry Feeds In Enugu Nigeria, International Journal of Life Science Biotechnology \& Pharm. Research, 2(3), pp:431-437

26. Maciorowski, K., Jones, F., Pillai, S., \& Ricke, S. (2004). Incidence, sources, and control of food-borne Salmonella spp. in poultry feeds. World's Poultry Science Journal, 60(4), 446-457

27. Zhao. C., Ge.B., Villena. D. J., Sudler. R., Yeh. E., Zhao. S., White. D. G., Wagner. D., Meng. J.,(2001), Prevalence of Campylobacter spp., Escherichia coli, and Salmonella Serovars in Retail Chicken, Turkey, Pork, and Beef from the Greater Washington, D.C., Area, Applied and Environmental Microbiology, 67(12), pp: 5431-5436

28. Matthew. O., Chiamaka. R., chidinma. O., (2017), Microbial Analysis of Poultry Feeds Produced in Songhai Farms, Rivers State, Nigeria. J MicrobiolExp 4(2), pp: 00110.

29. Hubbard. L. E., Givens. C. E., Griffin. D. W, Iwanowicz. L. R., Meyer. M. T., Kolpin. D. W., (2020), Poultry litter as potential source of pathogens and other contaminants in groundwater and surface water proximal to large-scale confined poultry feeding operations, Science of The Total Environment (735), 139459

30. Kibret, M., \& Abera, B. (2011). Antimicrobial susceptibility patterns of E. coli from clinical sources in northeast
Ethiopia. African health sciences, 11(1), pp:40-45.

31. Antunes. P., Mourão. J., Campos. J., Peixe. L., (2016), Salmonellosis: the role of poultry meat, Clinical Microbiology and Infection 22(2), pp:110-121

32. MEAD. G. C., (2000), Prospects for 'Competitive Exclusion' Treatment to Control Salmonellas and Other Food borne Pathogens in Poultry, The Veterinary Journal 159 (2), pp:111-123

33. Buncic. S., Sofos. J., (2012), Interventions to control Salmonella contamination during poultry, cattle and pig slaughter, Food Research International 45(2), pp: 641-655

34. Ma. Y., Ding. S., Fei. Y., Liu. G., Jang. H., Fang. J., (2019), Antimicrobial activity of anthocyanins and catechins against food borne pathogens Escherichia coli and Salmonella, Food Control, 106, 106712

35. Kunadu. A. P. H., YawOtwey. R., Mosi. L., (2020), Microbiological quality and Salmonella prevalence, serovar distribution and antimicrobial resistance associated with informal raw chicken processing in Accra, Ghana, Food Control, 118, 107440

36. Costa. P.M., Oliveira. M., Bica. A., Piresa. P., Bernardo. F., (2007), Antimicrobial resistance in Enterococcus spp. and Escherichia coli isolated from poultry feed and feed ingredients, Veterinary Microbiology, 120(1-2), pp:122-131

37. Iannetti. L., Neri. D., Santarelli. G. A., Cotturone. G., Vulpiani. M. P., Salini. R., Antoci. S., Serafino. G. D., Giannatale. E. D., Pomilio. F., Messori. S., (2020), Animal welfare and microbiological safety of poultry meat: Impact of different at-farm animal welfare levels on at-slaughterhouse Campylobacter and Salmonella contamination, Food Control, (109), 106921

38. Literature Review of Contaminants in Livestock and Poultry Manure and Implications for Water Quality, (2013), 
United States Environmental Protection Agency Office of Water (4304T), pp:1-125

39. Kommula. K. S. J.,(2011), Identification of hydrocarbon degrading bacteria by molecular characterization, VIT University, pp:1-71

40. Anjir. S., 1(2017), Degradation of Dyes used in Textile Industries by Bacteria isolated from local textile effluents, Degradation of Dyes used in Textile Industries by Bacteria isolated from local textile effluents, BRAC University, pp:1-79 41. Triple Sugar Iron (TSI) Agar (NCM0144), Technical Specification Sheet, (2019), Neogen culture media, pp:1-3

\section{How to cite this article:}

Rujuta Kedar Karkhanis, Yashsvi Udaybhai Raval, Devikaben Bharatbhai Vishani and Dhruv Girishbhai Patel. 2021. Isolation and Identification of Pathogenic Bacterial Contaminants associated with Poultry. Int.J.Curr.Microbiol.App.Sci. 10(05): 294-305.

doi: https://doi.org/10.20546/ijcmas.2021.1005.037 